\title{
Equity, exclusion and everyday science learning
}

\author{
EMILY DAWSON \\ Department of Science and Technology Studies
}

University College London

London, UK

Email | Twitter

A wake-up call

| Estimated reading time: 21 minutes.

Featured in the Spokes article collection Learning theory, Equity and inclusion What's the biggest problem affecting the science centre, science museum, informal science learning and science communication sectors? For me, it's how science learning and engagement practices cater for the dominant groups in our societies at the expense of minoritised groups. Many of us claim that 'science for all' is a core value in our professional practice. But my research shows that exclusion is embedded across the different practices that try to bring publics and sciences together. Informal science learning and science communication practices reproduce rather than ameliorate social inequalities. I know this is unacceptable to many of us, so what do we do?

I believe that if we are serious about developing meaningfully inclusive informal science learning and science communication practices, we need to understand how exclusion operates and purposefully work to transform these systems. My book, Equity, Exclusion \& Everyday Science Learning (Dawson 2019), explores how exclusion works in science museums and science centres, as well as science education, communication and engagement practices more broadly. The book comes from 12 years of research and draws on two years of ethnographic field-work with grass-roots community groups in South East London where I live. Five groups decided to take part in this research project; an Asian group, an Afro-Caribbean group, a Latin American group, a Sierra Leonean group and a Somali group. In the book I analyse their experiences of science, from school to work, from TV to politics, from home to science centres. I use the term 'everyday science learning' to try to think in broad terms, from the perspective of the research participants, about what kinds of practices are involved in science learning, engagement and communication. I draw on the data we generated through the research project to describe and analyse how exclusion works across the different practices of people's lives and, importantly, to develop a way to think about inclusion in everyday science learning. Together with illustrator Sophie Wang, I also summarized my book as a Zine: a few pages are reproduced in this article.

\section{Is exclusion a surprise?}

Do you remember the scene in the film "Black Panther" where the character Killmonger corrects a curator? After a series of her seemingly knowledgeable statements about various objects, he tells her that the axe she assures him is from Benin is actually from Wakanda. Of course "Black Panther" is fiction, but it gets so many things right about how dominant cultural institutions treat the knowledge, cultures, artefacts and practices of people from racialised backgrounds. 
During a research trip with me to a science museum people from the Sierra Leonean group involved in this research project were astonished to find mistakes in exhibit text about objects from Sierra Leone. Unlike Killmonger they didn't feel they could "correct" the museum or its curators. But they did laugh at the museum. The elders in particular were delighted to find they knew more than what they termed the "white man's museum". Less delightful (!) was the racial profiling by security, café and shop staff, the racist representations of people and cultures who weren't white, the sexist displays about women's bodies, the class war of who could and who couldn't afford souvenirs, as well as the sense of alienation, discomfort and 'Othering' the group experienced.

It won't surprise anyone who has been on the sharp end of exclusion from everyday science learning, whether in a museum or on TV, that my research found things were bad. It didn't surprise any of the groups who took part in this project. My book critically examines exclusion from everyday science learning and finishes with a conceptual framework to support inclusive change. I argue throughout the book that we fundamentally misunderstand how exclusion works and, as a result, misunderstand how inclusion works.

Exclusion was structured by racism, class discrimination, sexism and their intersections. Of course this is not an exhaustive list, different people will be affected by different structural inequalities (see for instance Cassidy, Lock, and Voss 2016, Levin 2010, Sandell, Dodd, and Garland-Thomson 2010, Middleton and Greene 2018, Achiam and Holmegaard 2017, Aguirre 2014). But structural inequalities, especially racism, class discrimination, sexism and their intersections were key problems for people in this research.

Participants' expectations of being excluded from informal science learning and science communication activities were fully realised in the practices we explored together. As a result, their decisions not to visit science centres, not to go to science talks, not to watch much science on TV and not to volunteer for local or national science consultations can only be understood as entirely strategic. These practices at best rendered their selves, cultures, histories, knowledges and practices invisible, and at worst, reproduced racist, classist and sexist ideologies that represented them as deficient.

\section{Reproducing inequalities in everyday science learning}

What does it mean to take a sociological approach to understanding everyday science learning? For me, it means taking seriously questions about how structural inequalities (not least racism, class discrimination, sexism) affect people's attitudes towards and experiences of science. But structural inequalities are not subjects that get much attention in research on informal science learning, museum studies or science communication. It is perfectly possible to read a whole journal about exhibit design, without finding a single word about how colonialism, white privilege, racism, androcentrism, heteronormativity, sexism, ablism, class discrimination or other forms of oppression affect the content, creation and communication of those exhibits. Yet outside this field so much research explores these topics in detail. If we don't think about how these kinds of structural inequalities contribute to our work in research and practice around everyday science learning, we are never going to be able to change entrenched inequalities around access, equity and exclusion. 
I came to this research from working in three museums, a community centre, science documentaries and two science communication research projects. It seemed clear to me that the staff, users, audiences and visitors involved in these various projects that tried to make science public were drawn from a fairly narrow public in demographic terms. That is, the people I worked with time and time again were white, middle/upper class, who typically lived with their families in cities, a pattern borne out in research about who uses science related educational and cultural resources in the UK (Ipsos MORI 2014, Department for Culture Media and Sport 2016, Falk et al. 2015). This picture is alarmingly similar in countries around the world (National Science Foundation 2012, Massarani and Merzagora 2014, OECD 2012).

To my surprise back in 2006 it was almost impossible for me to find anything report, paper, book, conference talk, website - that could help me understand why such seemingly different kinds of 'making-science-public' practices had such similar shortcomings. With hindsight, it seems obvious to me now that the inequalities that structured our lives are also entrenched in everyday science learning practices, whether those practices involve looking at YouTube videos about science or visiting a science festival. At the time however, it was difficult even to find research that could map out what the shape of everyday science learning inequalities.

I worked with colleagues who asked difficult questions about my research. All were fiercely proud of their work; trying to bring science to the public seemed unquestionably worthwhile. Who was I to suggest that their work contributed to the reproduction of racist, classist and sexist ideologies (amongst others) about who science was for? Couldn't I just focus on how best to communicate the crucial environmental messages of the day instead?

Through this project and writing my book I have developed better answers to these questions. Not least that structural inequalities are part of the soup of socialization that we all swim in. Understood from this perspective it is impossible to imagine that we might not reproduce such inequalities unless we work hard against them.

To me it still makes no sense to think about how best to communicate the important socio-scientific issues of the day unless you simultaneously figure out how to do so without exacerbating social inequalities. Environmental justice is, after all, a social justice issue. Better still, as I argue in the final chapters of the book, what if we figured out ways not just to stop reproducing racist, sexist, classist practices in science centres, but to disrupt and transform our societies more broadly?

\section{Moving away from deficits and crusades}

\section{“EVERYONE THINKS THE DOOR IS OPEN, BUT IT'S NOT REALLY, AND THAT'S PROBABLY BECAUSE THE PEOPLE IN CHARGE ARE QUITE COMFORTABLE AND DON'T WANT CRITICISM OR TO HAVE TO CHANGE" CONNIE, AFRO-CARIBBEAN GROUP.}

To understand how structural inequalities pervade all aspects of everyday science learning practice we must think carefully about how exclusion and inclusion are understood. As Connie from the Afro-Caribbean group argued in the extract above, museums and science centres can get away with seeming inclusive, whilst being 
profoundly exclusive.

In my book I argue that we have misunderstood exclusion in terms of deficiencies on the part of the excluded. In other words, the people who experience the problem, become the problem. As such people who don't enjoy everyday science learning practices are framed in terms of a double deficit. First, they are attitudinally deficient (because they are wrong not to like science and science-related activities). Second, they are behaviorally deficient (because they do the wrong kinds of activities and should instead be visiting museums). Of course, put so starkly this kind of framing seems immediately and profoundly wrong. But if you start to look for it it's easy to find time and time again in how exclusion is framed (see examples in the book!).

Deficit thinking is an indicator of structural inequalities at play. As Kalwant Bhopal (2018) argues, framing people from racialised groups who do not pursue the practices of dominant groups as themselves problematic, somehow deficient and responsible for their own exclusion is a significant feature of racist societies. This same practice of framing excluded people as responsible for their own exclusion - operates to reproduced class discrimination, sexism and more (Levitas 2004, Sandell 2007, Phipps 2008, Ahmed 2012). Usefully, deficit framings absolve everyone but the excluded from responsibility, and, as such institutional practices can easily be left unchanged.

Understanding exclusion in terms of deficits leads to framing inclusion as an assimilationist crusade. As such, inclusion in everyday science learning (whether in a science centre or a science story-telling evening) becomes about trying to persuade people that science-related content is amazing, that the medium for sharing it is fantastic and that their inclusion into this practice would benefit them. In other words, this is the evangelist's approach and it is firmly rooted in the double deficit model of exclusion. To be included means to be like the dominant group. From this perspective, inclusion is simply a matter of persuading people they are wrong not to get involved in whichever everyday science learning practice you are trying to sell. Assimilation is the price of inclusion. A price that, quite understandably, people do not want to pay.

Inclusion projects structured through a crusade logic typically involve practices that take science-related activities (in largely unchanged formats) to where particular communities are, or try to take those communities to un-changed science education, communication or engagement spaces.

\section{Can you think of any 'inclusion' activities by science centres and museums that have focused on getting 'excluded groups' into an institutional project, without changing any of the content, media, staffing, costs, marketing, exhibits or programming?}

Worse still are inclusion projects that use a crusade frame to justify tokenistic attempts to appropriate community insights, practices or sometimes simply bodies, to make an institution appear inclusive. Activities like this follow what Derek Bell (1980) calls interest convergence, because it seems like the institutional and community interests converge, but the benefits to the community are limited and 
controlled by the institution. Nancy Leong (2013) describes these power relations as racial capitalism because through such practices an institution profits by appearing to be inclusive, but communities experience such projects as extractive, and little actual change happens in the institution.

Obviously the people who worked with me on this research project led rich cultural, educational, social and political lives. That should go without saying. Many were seasoned political activists, many ran community-led cultural and/or educational activities ranging from massive festivals, to musical events, to weekend language schools. A few of them even loved science. But, as I discuss in the book, while they absolutely cannot be thought of as deficient in terms of attitudes or behaviours, they felt excluded from and indeed were excluded from everyday science learning practices.

\section{Inclusion as a threat?}

In the book I argue that unless we can better understand how exclusion operates and move away from deficits and crusades, we will struggle to create the kinds of transformative, meaningfully inclusive practices that so many people in science centres and museums are deeply committed to. Part of the reason that change is so hard, as Connie's quote above suggests, is because change is easily understood as a threat when our own privileges and vulnerabilities are called into question. It is so much easier to carry on with 'business as usual' and look away from practices that are hard to understand because you don't experience them as problematic (i.e. racist/sexist/classed/+) yourself.

A key part of the privilege of being from a dominant group is that your privilege is normalized and rendered somewhat invisible. As Peggy McIntosh $(1989,10)$ argued, if you belong to the dominant group in terms of your 'race'/ethnicity your racial privilege is the equivalent of an "invisible knapsack", providing you with useful tools to help you through your life. But making this knapsack visible means surfacing the structural inequalities that make some people successful at the expense of others. Taking structural inequalities (and structural privileges) seriously can be deeply threatening. As Robin DiAngelo (2018) argues ideas, language and practices that threaten to disturb white people's sense that their privileges are anything but earned and deserved are perceived as problematic because they have the power to call such privileges into question.

These ideas are also useful as a way to think about other forms of privilege you may enjoy, and how they do (or don't) work together. In short, scholars of social justice, from critical race theorists, to gender theorists, to class theorists and those working on intersectional analyses agree that to address structural inequalities in educational, cultural and/or political practices we first have to be clear about what they are, how they affect us, our work and our societies (Crenshaw 1991, Rollock et al. 2014, Bennett et al. 2009, Saha 2018). Importantly, although swimming in that soup of socialization means we can't escape the influence of structural inequalities, as Paul Gilroy (2002) reminds us, that doesn't let us personally off the hook. Surely a core part of professional practice in everyday science learning has to include taking the challenges of social justice, structural inequalities and meaningfully inclusive practice seriously? 


\section{Taking inclusion seriously}

As you can probably tell by now, the key implication of the last 12 years of my research is that it is more than time for change. But what does change look like? In thinking about how everyday science learning could be usefully disrupted and transformed, I believe we need to radically reimagine practice. What would need to happen to actively pursue anti-racist, anti-colonialist, anti-classist, anti-sexist everyday science learning practices, that were neither ableist, heteronormative of otherwise oppressive? Clearly this is what Toni Dancstep from the Exploratorium in San Francisco once described to me as the "creative challenge" of our time!

Obviously I cannot hope to list practice-based solutions for every inclusion challenge people may face, but my hope is that the ideas discussed in this article, my book, the zine and related academic papers provide tools (language, concepts, examples) that support the development of more inclusive everyday science learning practices. The conceptual framework that I develop in the book combines different theories within social justice scholarship to think about the distribution of access and resources (sometimes called equality) at the same time as thinking about recognition, respect and value (sometimes referred to as equity) (Dawson 2019, Fraser and Honneth 2003, Dawson 2017). This dual approach to social justice is key for understanding exclusion from and non-participation in everyday science learning, and helps to foreground multiple perspectives. The framework can be used to design or evaluate practices intended to be more inclusive (see Figures 1 \& 2/Figure 1). In essence, exclusive business-as-normal practices sit within the bottom, left-hand square. Here the groups who feel welcome, represented and can access everyday science learning easily are the dominant ones. The other three squares represent different ways to address exclusion/inclusion, with the top, right-hand corner as the goal.

To think through each square in detail, I use a second set of concepts drawn from community learning research (Porter 1998, Grabill 1998, Dawson 2014).

Three lenses, infrastructure access, literacies and community acceptance help to break down the different aspects of how everyday science learning practices might be understood from a social justice perspective. Each lens addresses issues of powersharing in various ways by taking different kinds of practices as their starting point. Examples include thinking about who is on your board of trustees, who shapes the rules of how an exhibition works or who takes responsibility for change (see Figure 2 below).

Taken together, the combined model of social justice and the three lenses for thinking about inclusive practice help to think through what might (and might not) be inclusive practice. I see each lens as working with the next in multiple, mutually enhancing ways. Since each lens can be understood on a continuum from weak to strong enactments of social justice, these concepts can be used to map activities and to think about how different inclusion practices complement or undermine one another. For example, Figure 4 (below) outlines how inclusive everyday science learning practices might be described using these ideas. In the green box (number 1) would be practices that radically transform how power works in a particular institution, changing whose knowledge, bodies and practices count in that space, with strong support from people previously inside and outside the institution. The yellow boxes ( 2 and 3 ) represent ways to think about partially inclusive practices and their limitations. In box 2 , for 
example, you could think about attempts to generate more visitors without changing or challenging who and what is represented in an exhibition. Similarly, in box 3, you could think about attempts to change whose knowledge, bodies and practices count in a museum where entry fee structures and marketing practices remain unchanged. In both boxes, infrastructure access, literacies and community acceptance are only partially transformed, in box 2 in terms of redistributive access only, and in box 3 in terms of recognition, value and relational social justice only. As you can see, the model shows how useful it can be to think of social justice in multiple ways.

\section{An inclusive future?}

What do we want when we think about what meaningfully inclusive everyday science learning could mean? Nancy Fraser $(2003,7)$ argued that "the goal, in its most plausible form, is a difference-friendly world, where assimilation to majority or dominant cultural norms is no longer the price of equal respect". Of course there will always be people who won't want to take part in every kind of everyday science learning practice. But for me, taking an inclusive approach means that our goal must be about everyone being able to choose to have a meaningful, relevant and respectful everyday science learning experience if they want to, one where their own communities, knowledges and practices are valued. My hope then, is that by sharing what I've learned about exclusion and inclusion in everyday science learning, people feel more confident in developing inclusive practices.

Addressing exclusion/inclusion means being active, being brave, taking a stance, building relationships, being patient and being humble. Everyday science learning holds vast potential for disrupting rather than reproducing social disadvantages and structural inequalities. I recognise the idealism inherent in writing about change, but I find comfort in the oft-quoted words of Audre Lorde (1984, 140-141) who wrote "revolution is not a one time event. It is being always vigilant for the smallest opportunity to make a genuine change in established, outgrown responses". From this perspective, each attempt to develop meaningfully inclusive, equitable practice, no matter how small, helps us to learn more and to embrace this challenge. I am still learning, and there is still so much more to learn.

You fill find my book here on the Routledge website. Don't hesitate to email me if you want to find out more about the book.

You can download the Zine version here. It was developed by Sophie Wang - see her Twitter account for more of her work.

\section{REFERENCES}

Achiam, Marianne, and Henriette T. Holmegaard. 2017. "Informal science education and gender inclusion." In Embracing the other. How the inclusive classroom brings fresh ideas to science and education, edited by L.S. Heuling, 32-40. Flensburg: Flensburg University Press.

Aguirre, Claudia. 2014. "Science Centers. Which roles can they play to participate in a city social reconstruction?" Journal of Science Communication 13 (2):1-12. Ahmed, Sara. 2012. On being included: Racism and diversity in institutional life. Durham and London: Duke University Press.

Bell, D. A. . 1980. "Brown v. Board of Education and the interest- convergence dilemma." Harvard Law Review 93 (3):518 - 533. 
Bennett, Tony, Mile Savage, Elizabeth Silva, Alan Warde, Modesto Gayo-Cal, and David Wright. 2009. Culture, class, distinction. Abingdon and New York: Routledge. Bhopal, Kalwant. 2018. White privilege: The myth of a post-racial society. Bristol: Polity Press.

Cassidy, Angela, Simon J. Lock, and Georgina Voss. 2016. "Sexual Nature?

(Re)presenting Sexuality and Science in the Museum." Science as Culture 25

(2):214-238. doi: 10.1080/09505431.2015.1120284.

Crenshaw, Kimberle. 1991. "Mapping the margins: Intersectionality, identity politics, and violence against women of color." Stanford Law Review 43:1241-1299.

Dawson, E. 2019. Equity, exclusion \& everyday science learning: The experiences of minoritised groups. London and New York: Routledge.

Dawson, Emily. 2014. "Equity in informal science education: developing an access and equity framework for science museums and science centres." Studies in Science Education 50 (2):209-247.

Dawson, Emily. 2017. "Social justice and out-of-school science learning: Exploring equity in science television, science clubs and maker spaces." Science Education 101 (4):539-547.

Department for Culture Media and Sport. 2016. Taking Part: longitudinal report 2016. London: Department for Culture Media and Sport,.

DiAngelo, Robin. 2018. White fragility: Why it's so hard for white people to talk about racism: Beacon Press.

Falk, John, Lynn D Dierking, Jonathan Osborne, Matthew Wenger, Emily Dawson, and Billy Wong. 2015. "Analyzing Science Education in the United Kingdom: Taking a System-Wide Approach." Science Education 99 (1):145-173.

Fraser, Nancy. 2003. "Social justice in the age of identity politics: Redistribution, recognition, and participation." In Redistribution or recognition? A politicalphilosophical exchange, edited by Nancy Fraser and Axel Honneth, 7-109. London and New York: Verso.

Fraser, Nancy, and Axel Honneth. 2003. Redistribution or recognition? A politicalphilosophical exchange. London and New York: Verso.

Gilroy, Paul. 2002. There ain't no Black in the Union Jack. Second ed. Abingdon:

Routledge.

Grabill, Jeffrey T. 1998. "Utopic visions, the technopoor, and public access: Writing technologies in a community literacy program." Computers and Composition 15 (3):297-315.

Ipsos MORI. 2014. Public Attitudes to Science 2014. London: Department for Business, Innovation and Skills.

Leong, Nancy. 2013. "Racial capitalism." Harvard Law Review 126 (8):2153-2226. Levin, A.K. 2010. Gender, Sexuality and Museums: A Routledge Reader. Abingdon and New York: Taylor \& Francis.

Levitas, Ruth. 2004. "Let's hear it for Humpty: Social exclusion, the third way and cultural capital." Cultural Trends 13 (2):41 - 56.

Lorde, Audre. 1984. Sister Outsider. Berkeley: Crossing Press.

Massarani, L., and M. Merzagora. 2014. "Socially inclusive science communication." Journal of Science Communication 13 (2):1-2.

McIntosh, Peggy. 1989. "White privilege: unpacking the invisible knapsack." Peace and Freedom July/August:10-12.

Middleton, Margaret, and Alicia Greene. 2018. "Trans Narratives in Children's

Museums." Journal of Museum Education 43 (3):220-227.

National Science Foundation. 2012. Science and Engineering Indicators 2012. 
Arlington, Virginia: National Science Foundation.

OECD. 2012. Education at a glance 2012: OECD indicators. http://www.oecdilibrary.org/education/education-at-a-glance-2012 eag-2012-en: OECD Publishing. Phipps, Alison. 2008. Women in science, engineering, and technology: three decades of UK initiatives. Sterling, VA: Trentham Books.

Porter, J.E. 1998. Rhetorical Ethics and Internetworked Writing. Greenwich, CT and London: Ablex Pub.

Rollock, Nicola, David Gillborn, Carol Vincent, and Stephen J Ball. 2014. The colour of class: The educational strategies of the Black middle classes. London and New York: Routledge.

Saha, Anamik. 2018. Race and the cultural industries. Cambridge: Polity Press. Sandell, Richard. 2007. Museums, prejudice and the reframing of difference. London and New York: Routledge.

Sandell, Richard, Jocelyn Dodd, and R. Garland-Thomson. 2010. Re-Presenting disability: Activism and agency in the museum. Abingdon \& New York Routledge. 